\title{
Special Announcement
}

\author{
ELEVENTH INTERNATIONAL CONGRESS \\ OF CYBERNETICS AND SYSTEMS \\ Dedicated to the memory of the late \\ Professor Frank H. George \\ Brunel University, Uxbridge (West London), \\ Middlesex, United Kingdom, 23-27 August 1999
}

\section{TOPICS OF INTEREST TO THE CONGRESS}

Artificial Intelligence, Automation and Robotics, Behavioural Sciences, Biocybernetics, Chaos and Fractals, Cognition, Computers, Cybernetics and Art, Cybernetics and Philosophy, Economic Cybernetics, Educational Cybernetics, Environmental Cybernetics and Ecosystems, Genetic Algorithms and Neural Networks, information, Complexity and Self-organisation, Management and Cybernetics, medical Cybernetics, Sociocybernetics, Systems and Cybernetics Methodologies.

\section{PARTICIPATION}

The deadline for the reception of abstracts having passed, it is still possible to participate without submitting a paper.

\section{FEE}

75 pounds sterling to be paid:

a) By a bankers draft, in pounds sterling, made to WOSC and sent to Prof. J. Rose, 5 Margate Road, Lytham-ST. Annes FY8 3ET, United Kingdom, before 31 July 1999. b) Cash, in pound sterling, at the registration desk of the Congress.

The fee entitles one to obtain the Congress Proceedings as well as to book rooms at the Halls of Residence of Brunel University (see below).

\section{ACCOMODATION}

Rooms may be booked at the Halls of Residence of Brunel University at prices modest compared to those of London Hotels. The rooms are only available from August 22 to 28 by writing to Prof. J. Rose before the end of July (address above, tel. +44(0) 1253725 114).

General enquiries to: Prof. R. Vallée

Dir.-Gen. WOSC

2, rue de Vouillé

75015 PARIS

France

Fax \& Tel. +33145336246

(Home) 